\title{
The Role of Online Guest Review Sites in the Hospitality Industry: Evidences from Managers' Perspectives
}

\author{
By \\ Omnia Tarek El- Mohamed Abd \\ Dereny' El-Fattah Zohry \\ Ahmed Hassan \\ Abdou $^{r}$
}

\begin{abstract}
Consumers now rely heavily on online reviews as part of their decision-making process and as a primary source of information. The advancement of online review sites on the Internet has significantly changed the hospitality industry landscape. Hotel customers are increasingly turning to online review sites as a means of providing feedback on their stay. In this study we attempt to investigate the perceptions of the hotels' managers in a sample of Four and Five-star hotels in Greater Cairo towards guest review sites through, identifying to what extent the investigated hotels involved in the online guest review communities, and exploring the advantages and disadvantages of these sites to their properties. To do this, a questionnaire was distributed to a sample of managers in charge of managing and handling guest reviews in the hotels under investigation. A total of $r \mathrm{r}$ managers participated in the field study were selected conveniently. The study's findings show that the respondents believe that guest review sites play a
\end{abstract}

\footnotetext{
'Faculty of Tourism \& Hotels, Mansoura University, Egypt

Faculty of Tourism \& Hotels, Mansoura University, Egypt

${ }^{r}$ College of Arts, King Faisal University, Kingdom of Saudi Arabia
} 
significant role in the hospitality industry. Guest reviews and responding to them on time have always been a vital part of the hotel industry. Overall, the investigated respondents confirmed that they review and respond to guest reviews on a regular base which reflect their responsiveness to online guest reviews. Fake negative review is the main challenge that faces them. Upon the study findings, implications for hotel managers have been suggested.

Key words: e-WOM - Guest Review - Online Review Sites - TripAdvisor

\section{Introduction}

Recently, the Internet has transformed the nature and characteristics of the media and communications sector in unprecedented ways (Buhalis and Law $r . . \wedge$ ). The Internet, unlike any other medium, has given the corporate world a worldwide dimension and has become a unique universal source for information (Dellarocas, Zhang and Awad, r...V). Online customer reviews and social media comments have supplemented or perhaps completely replaced conventional sources of information (i.e., T.V, newspapers, and brochures). According to Racherla, Mandviwalla, \& Connolly $(r \cdot \mid r)$, Consumer internet reviews were deemed more valuable by 09 percent of $0,0$. BizRate customers than expert reviews. Furthermore, internet review sites affect purchasing decisions more than any other source of information, implying that social media plays a major role in marketing (DoubleClick, $\uparrow \ldots \varepsilon$ ).

Promotion-oriented customers are more attentive to reviews, such as the attractiveness of the hotel location, the number of recommended restaurants near the hotel, and the 
availability of free coupons, when making hotel reservation decisions, in order to gain more benefits from hotel guests who have previously stayed at the same hotel. Meanwhile, prevention-minded customers have a strong desire to reduce risk, therefore they monitor unfavourable review remarks such as poor value for money, poor service quality, and bad location. For consumers who have never used a business before, online reviews from previous customers are valuable sources of information (Pan, MacLaurin, \& Crotts, r...V).

Consumers now rely heavily on online reviews as part of their decision-making process and as a primary source of information (Molinillo, et al., r.17). They also give a feedback mechanism for service providers to track guests' emotions and experiences, as well as any needed modifications. As a result, favourable or negative online reviews have the potential to help or hurt a hotel's image and reputation (Jeonga \& Jang, $r \cdot \backslash \backslash)$ ).

The success of popular websites like TripAdvisor and Booking.com shows that customers' online interaction for the purpose of travel is represented via online reviews (Vermeulen and Seegers, $r \ldots q$ and Xiang and Gretzel, $r \cdot 1 \cdot)$. Customer reviews, as well as review score and anecdotes, have the power to improve the reputation of the firm or destination (Sparks and Browning, r. 1)). Hotels can learn what customers like and dislike by monitoring comments on guest review sites. A more thorough investigation could also disclose what extras clients are ready to pay for. According to O'connor $\left(r_{\bullet} \cdot \cdot\right)$, such an examination could lead to a full understanding of customers' characteristics and behaviour patterns. 
Several studies have looked at how online consumer reviews affect marketing techniques (Chen, Fay \& Wang, r. I'; Chevalier and Mayzlin, r.. ฯ ), consumer decision making (Sen and Lerman $r . . \vee$ ), and sales forecasting (Dhar and Chang, $Y . .9$ ). In order to close the gap in scientific knowledge that exists, this study seeks to investigate the perceptions of the hotels' managers in a sample of Four and Five-star hotels in Greater Cairo towards guest review sites through; identifying to what extent the investigated hotels involved in the online guest review communities, determining how hotel managers collect, handle and monitor guests' reviews and exploring the motivators to engage in guest review sites, and the advantages and disadvantages of these sites to their properties. Additionally, the study seeks to test the following hypothesis:

1. There are no statistically significant differences between perceptions of the investigated respondents towards advantages $\&$ disadvantages of online guest review sites that refer to gender.

$r$. There are no statistically significant differences between perceptions of the investigated respondents towards advantages \& disadvantages of online guest review sites that refer to age.

$r$. There are no statistically significant differences between perceptions of the investigated respondents towards advantages \& disadvantages of online guest review sites that refer to level of education.

$\varepsilon$. There are no statistically significant differences between perceptions of the investigated respondents 
towards advantages $\&$ disadvantages of online guest review sites that refer to length of work experience.

The current study is structured as follows: in addition to the current introduction, section $r$ presents the literature review regarding the concept of guest review sites in the hospitality industry. Section r "Research methodology" concerns the method adopted for the development of the statistical study. Furthermore, the findings of the questionnaire form that have been developed and directed to the investigated managers have been presented and discussed in section $\varepsilon$ (Results and Discussion). Finally, section ${ }^{\circ}$ pertains to the conclusion, and implications of the study.

\section{r. Literature Review}

r, I Guest Review Sites in the Hospitality Industry

Online hotel reviews are gradually becoming the most popular trending instrument for customer behaviour research, with the potential to deliver a wealth of information about customers' thoughts and attitudes (Dellarocas, $r \cdot r$ ). According to Filieri and McLeay $(Y) \varepsilon)$, the travel industry views an online review (OR) as an electronic counterpart of conventional word-of-mouth (WOM), which consists of customer comments about their experiences with products, services, and brands. This online sharing of opinions is called e-WOM (electronic word of mouth) (Filieri, $r \cdot 10$ ). E-WOM is described as "any good or negative statement made by future, actual, or past consumers about a product, service, or business, which is made available to a multitude of individuals and institutions over the Internet" and is a technical evolution from WOM (Filieri \& McLeay, $r \cdot 1 r$ ). 
The Role of Online Guest Review Sites in the Hospitality Industry: Evidences from Managers' Perspectives

With regard to Tourism and hospitality industry, the online reviews posted by customers on guest review platforms (i.e., TripAdvisor) play important roles. Online reviews enable tourism and hospitality businesses to: shape customers' awareness, expectations, and perceptions; reach out and gain more customers at a low cost; predict and affect sales or revenues; effectively improve and develop new and current products or services; audit the company's image and reputation on the Internet; and build relationships with customers and facilitate consumer repurchase, analyse behavioural trends and respond to unfavourable reviews before they become widespread, enhance customer happiness by responding to consumer feedback, and provide feedback to employees (congratulate and reward after positive review or train after negative review) (Kim, Lim \& Brymer, r.10; Molinillo, FernándezMorales, Ximénez-de-Sandoval, \& Coca-Stefaniak, Y.17). According to experts, hotel guest reviews are becoming increasingly important and influential in the decisionmaking process and hotel selection for clients (BulchandGidumal, Melián-González, \& López-Valcárcel, Y.11). Customers can use online reviews to pick where to go and what to buy because they are more independent and hence more reliable and up-to-date. These reviews assist customers in evaluating alternatives, reducing purchase uncertainty, increasing product awareness, providing travel ideas, assisting others in avoiding places, assisting others in imagining what a place will be like, and increasing the likelihood of consumers considering making a booking (O'Connor, $Y \cdot) \cdot$ and Gretzel \& Yoo, $r \cdots \wedge)$. Because of its considerable influence on customers' ultimate purchasing decisions, these online evaluations or recommendations

\section{$\Lambda$}


types of e-WOM have grown increasingly crucial. According to studies, online consumer reviews have a significant impact on product/service performance in the hotel industry (Cheng \& Loi, $Y \cdot \mid \leqslant$ ). Consumers in the hospitality industry find it difficult to assess the quality of services before using them, thus they rely heavily on the perceived image and reputation (O'Connor, $Y \cdot{ }^{\prime} \cdot$; Yang, Mueller, \& Croes, $\left.Y_{\cdot} \mid{ }^{7}\right)$. This distinct feature means that people have a great deal of ambiguity about their choices and, as a result, require a lot of knowledge to lower perceived risks and make well-informed judgments. The most crucial duty is to get customers to regularly post their experiences on social media, which keeps them coming back and informing others what a fantastic hotel/it is $(\mathrm{Gu}$ and $Y e, Y \cdot \mid \varepsilon)$.

Hotel reviews published on well-known internet travel communities are regarded as valuable and trustworthy, eliciting favourable or negative reactions to a hotel (Casalo, Flavian, Guinaliu, \& Ekinci, $\left.r^{-10}\right)$. Both the number (volume) and the degree of positivity (valence) of online reviews have been shown to matter as a signal of hotel popularity and customer choice, which can influence normative behaviour ("follow the crowd") (Kwok, Xie, \& Richards, $r \cdot \mid \mathrm{V})$.

The positive (benefits gained) or negative (benefits lost) product qualities are the focus of message valence. When it comes to product evaluations, consumers value negative information more than positive information. Furthermore, negative information spreads faster than positive information, as unhappy consumers are more inclined to talk about their experiences than satisfied customers. Positive reviews, in contrast to negative reviews, are 
The Role of Online Guest Review Sites in the Hospitality

Industry: Evidences from Managers' Perspectives

primarily concerned with glorifying a company's quality oriented, such as making recommendations to others (Brown, Barry, Dacin, \& Gunst, r...o). Positive internet reviews are widely acknowledged as an effective tool for promoting a hotel's products and services. Strongly good ratings led to a large increase in product sales, according to Clemons, Gao, and Hitt ( $\uparrow \cdots \uparrow)$.

The successful operations of online markets necessitate the provision of accurate information to customers in a transparent manner. One of the greatest obstacles to the Consumer Protection Law on the Internet is fake reviews on digital platforms (Fiedler, M., \& Kissling, r.r.). "Deceptive evaluations produced with the goal to mislead consumers in their purchase decision-making, frequently by reviewers with little or no actual expertise with the products or services being reviewed," according to the definition of fake reviews (Zhang, Zhou, Kehoe \& Kilic, r. 1 7, p. \{०V). If there are bad reviews, purchase intent may be harmed since unfavourable comments might provide credence to the entire review, damaging the hotel's reputation (Liang, Ekinci, Occhiocupo, \& Whyatt, $r \cdot 1 r)$. A recent survey of the literature on online reviews in tourism and hospitality revealed two primary study priorities: (1) determining the impact of online reviews on visitors' purchasing decisions, and $(r)$ determining how hospitality organisations should handle online reviews (Schuckert, Liu, X., \& Law, $r^{+10}$ ).

Managing guest online reviews posted on online communities as part of e-WOM tools is critical for hotels to improve and grow their competitiveness: it is the result of an integrated process in which information and interactions serve as both drivers and enablers. As a motivator, e-WOM encourages hotel managers to participate in market 
intelligence gathering and information generation. Such information can be used to determine a hotel's strengths and shortcomings, the service elements that consumers value most, the competitive gaps that need to be filled in order to improve services, and the online reputation of competitors (Litvin, Goldsmith, \& Pan, Y..^). This information can also be utilised to aid decision-making by enabling new service development and improved segmentation (Sigala, Christou, \& Gretzel, $r \cdot 1 r$ ), adjusting pricing strategies, and maintaining more informative choices based on data monitoring (Sigala, Christou, \& Gretzel, Y.1 r). (Levy, Duan \& Boo, $r \cdot \mid r)$. As an enabler, e-WOM enables hotel managers to create dynamic connections with clients through interactive communication flows (Cantallops and Salvi, $Y \backslash\{)$. This entails encouraging visitors to participate in online discussions, encouraging them to leave comments, and reacting to guest complaints in order to demonstrate that service failures and customers' issues are being addressed, as well as providing reassurance (Aureli and Supino, $r \cdot \mid v)$.

\section{r. Research Methodology}

As mentioned previously, the current study aims to investigate the perceptions of the hotels' managers in a sample of Four and Five-star hotels in Greater Cairo towards guest review sites through, identifying to what extent the investigated hotels involving in the online guest review communities, and exploring the advantages and disadvantages of these sites to their properties.

\section{r, I Study Population and Sample}


The Role of Online Guest Review Sites in the Hospitality Industry: Evidences from Managers' Perspectives

The population of this study was composed of hospitality managers in charge of handling and managing online guest reviews in Four and Five-star hotels in Greater Cairo. According to the Egyptian Hotel Association $(r \cdot 17)$, the total number of Four and Five-star hotels in Greater Cairo was 01 hotels ( $r$ r Four-star and $r q$ Five star). To fulfil the study's goal, a questionnaire was created and sent to the person in charge of handling and reacting to guest reviews posted on various guest review sites in the hotels under investigation. A sample of $r$ p participants, representing $7 r \%$ of the total Four and Five-star hotels in Greater Cairo, was surveyed (Egyptian Hotel Association, Y • 17).

The participants in the study were chosen using a convenience sampling approach, which is "a sort of nonprobability sampling in which people are sampled solely because they are 'convenient' data sources for researchers" (Lavrakas, $Y \cdots \wedge$ ). When randomization is not practicable due to a vast population or researchers' limited resources, time, or manpower, it is often utilised (Etikan, Musa \& Alkassim, $Y_{\cdot}$ 17). As a result of the researchers' limited time and manpower, they adopted a convenience sampling strategy in addition to those individuals who were more cooperative and eager to engage in the field study.

\section{$r$, r Questionnaire Form Structure}

There were three sections to the questionnaire form. The first section of the survey asked participants to provide demographic information such as their gender, age, level of education, and work experience in the hotels under investigation. The second section sought to identify the repeatness of online guest review site visit, the most used guest review site, and the main reason which motivated the 
investigated hotels to engage in online guest review sites. The third section was intended to reveal the perceptions of the investigated respondents towards advantages and disadvantages of guest review sites by utilizing a five-point Likert-type scale (strongly agree $=0$, agree $=\varepsilon$, neutral $=r$, disagree $=r$ and strongly disagree $=1$ ) to determine the levels of agreement with the statements investigated.

Statistical Package for the Social Sciences (SPSS) version ro, - for Windows was used to compute and analyse the data collected from the respondents. Frequency counts, percentage distributions, mean and standard deviation were calculated and analysed. Kolmogorov- Smirnova and Shapiro Wilk tests were used to identify the normality of participants' responses. To compare differences between the independent groups, the Mann-Whitney $\mathrm{U}$ and Kruskal-Wallis tests were utilised.

\section{£. Results and Discussion}

\section{\&, ' Respondents' Demographic Data}

As shown in Table 1, the data collected from the investigated respondents $(n=r r)$ illustrated that, the majority of participants were males, constituting $07, r \%(n=$ $1 \wedge)$. With regard to respondents' ages, participants aged more than $\varepsilon$ - years were the higher category ( $\leqslant r, v \%$ ), followed by those with an average age ranging from $r \cdot$ to $\varepsilon$ years $(r \vee, 0 \%)$, while the youngest, i.e., less than $r$. years, amounted only $\wedge, \wedge \%$. In terms of the respondents' level of education, the highest category $(\neg \wedge, \wedge \%, n=r r)$ had university degrees. With regard to the respondents' job experience in the hotel industry, the higher percentage $(\{\uparrow, \vee \%)$ pertains to participants with an average work experience ranged from 0 to $1 \cdot$ years. 
The Role of Online Guest Review Sites in the Hospitality

Industry: Evidences from Managers' Perspectives

Table 1: Respondents' demographic data

\begin{tabular}{|c|c|c|c|}
\hline \multirow{2}{*}{ Dimension } & \multirow{2}{*}{ Variable } & \multicolumn{2}{|c|}{ Statistics } \\
\hline & & Freq. & $\%$ \\
\hline \multirow{2}{*}{ Gender } & Male & 11 & $07, r$ \\
\hline & Female & $1 \varepsilon$ & $\varepsilon r, V$ \\
\hline \multirow{3}{*}{ Age } & Less than ${ }^{\Gamma} \cdot$ years & 7 & $\overline{1 \wedge, \wedge}$ \\
\hline & From $r \cdot$ to $\leqslant \cdot$ years & Tr & $r V, 0$ \\
\hline & More than $\varepsilon \cdot$ years & $1 \varepsilon$ & $\varepsilon r, V$ \\
\hline \multirow{2}{*}{$\begin{array}{c}\text { Level of } \\
\text { Education }\end{array}$} & University degree & TY & $7 \Lambda, \Lambda$ \\
\hline & Post-graduate degree & $1 \cdot$ & $r, Y$ \\
\hline \multirow{3}{*}{$\begin{array}{c}\text { Work } \\
\text { Experience }\end{array}$} & Less than ${ }^{\circ}$ years & 7 & $\overline{1 \wedge, \wedge}$ \\
\hline & From ${ }^{\circ}$ to $1 \cdot$ years & Is & $\varepsilon r, V$ \\
\hline & More than $1 \cdot$ years & TY & $r V, 0$ \\
\hline
\end{tabular}

\section{¿, r Repeatness of Online Guest Review Site Visit}

This question aims at identifying to what extent the investigated respondents concern reviewing, analyzing, and responding to online guest reviews. All of the investigated respondents $(1 \ldots \%)$ confirmed that they review and respond to guest reviews on a regular base which reflect their responsiveness to online guest reviews. This finding is in line with that of Baltescu $(r \cdot 17)$, who stated that timely online answers play a crucial role in enhancing customer satisfaction, particularly in the case of unfavourable evaluations. Customer dissatisfaction might be lessened by hotel management providing explanations and apologies in order to regain guests' trust, which would improve the company's financial performance.

\section{$\varepsilon, \boldsymbol{r}$ The Most Used Hotel Guest Review Site}

This question aims to explore the most guest review site used by the investigated respondents to identify the guests' 
perceptions towards the quality of their hotel experience. The investigated respondent asked to select only one site.

Table $r$ : The most used hotel guest review site

\begin{tabular}{|l|c|c|}
\hline \multicolumn{1}{|c|}{ Variable } & Freq. & $\%$ \\
\hline TripAdvisor.com & ro & $\vee \wedge, 1$ \\
\hline Google.com & $r$ & \urcorner, $r$ \\
\hline Booking.com & 0 & 10,7 \\
\hline Expedia.com & - & - \\
\hline Hotels.com & - & - \\
\hline Other & - & - \\
\hline Total & r & 1. \\
\hline
\end{tabular}

As shown in Table $r$, the vast majority of the investigated respondents, constituting $\vee \wedge, \vdash \%\left(n=r_{0}\right)$, mentioned that TripAdvisor is the most used hotel guest review site to identify the guests' perceptions towards the quality of their hotel experience, followed by Booking.com $(10,7 \%)$ and Google $(\Im, r \%)$ respectively. This finding is consistent with Xie, Zhang, and Zhang ( $(\cdot 1 \xi)$, who noted that when it comes to hotel managers' online presence, TripAdvisor is frequently the first port of contact. Moreover, TripAdvisor, according to Sayfuddin and Chen $(Y \cdot Y)$ ), is not only the pioneer of online travel intermediation but also a specialist in hotel booking. In terms of the number of unique users, the website has constantly been listed as the most popular website for hotel and restaurant reservations in the United States (Statista, $r \cdot r$ ) $)$.

\section{$\varepsilon, \Gamma$ Motivation for Engaging in Online Guest Review Sites}

The goal of this question is to figure out what drove the hotels under investigation to use online guest review services. The responders were only allowed to choose one 
explanation. As shown in Table $r$, the main reason to handle guest reviews was increasing the hotel's image and reputation among customers and competitors, constituting or, $1 \%(n=1 v)$. Hotels' commitment to customers' trustfulness, reducing hotel's advertising costs, increasing hotels' profits, as well as increasing hotel's market share

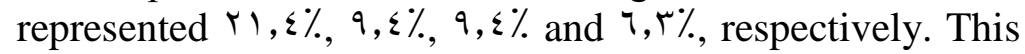
finding is in line with the findings of Yap, Soetarto, \& Sweeney $(Y \cdot 1 r)$, who concluded that the main reasons behind engaging in online guests' reviews was company's self enhancement through increasing the company's reputation and improving customer satisfaction about products and services provided.

Table $r$ : Motivation for engaging in online guest reviews sites

\begin{tabular}{|c|c|c|}
\hline Variable & Freq. & $\%$ \\
\hline $\begin{array}{l}\text { Increasing the hotel's image and reputation } \\
\text { among customers and competitors }\end{array}$ & IV & or, 1 \\
\hline $\begin{array}{l}\text { Hotels' commitment to customers' } \\
\text { trustfulness }\end{array}$ & $\mathrm{v}$ & r), \\
\hline Reducing hotel's advertising costs & $r$ & $9, \varepsilon$ \\
\hline Increasing hotel's market share & r & $7, \Gamma$ \\
\hline Increasing hotels' profits & $r$ & $9, \varepsilon$ \\
\hline Total & rT & $1 \cdots$ \\
\hline
\end{tabular}

$\varepsilon, \xi$ Perceptions of the Investigated Respondents towards Advantages Online Guest Review Sites

These questions were designed to demonstrate how the respondents felt about the benefits of online guest review sites. Using a five-point Likert-type scale ( $l=$ strongly disagree to $0=$ strongly agree), the respondents were asked to identify their perceptions of the researched variables. The 
data gathered from the investigated respondents is shown in the table below.

Table r: Perceptions of the investigated respondents towards advantages of online guest review sites

\begin{tabular}{|c|c|c|}
\hline Variable & Mean & SD. \\
\hline \multicolumn{3}{|l|}{ Guest review sites.............. } \\
\hline $\begin{array}{l}\text { 1. Are valuable tools for distributing } \\
\text { information and gathering data of } \\
\text { customers' hotel experience. }\end{array}$ & $\varepsilon, 0$ & $\cdot$, TYY \\
\hline $\begin{array}{l}\text { r. Are important to building } \\
\text { relationship with customers and } \\
\text { facilitate } \\
\text { interaction. }\end{array}$ & r,q६ & $\cdot, 9 \leqslant \wedge$ \\
\hline $\begin{array}{l}\text { r. Highlight areas for improvement } \\
\text { in hotel's service process. }\end{array}$ & $\varepsilon, \cdot T$ & $\cdot, 999$ \\
\hline $\begin{array}{ll}\text { ₹. Improve customer trust and } \\
\text { confidence of hotel business. }\end{array}$ & $\xi, \varepsilon)$ & $\cdot, V \mid Y$ \\
\hline ๑. Improve search engine results. & $\varepsilon, \cdot 9$ & $\cdot, \wedge \backslash \wedge$ \\
\hline $\begin{array}{l}\text { 7. Help hotel to collect and exchange } \\
\text { market information through online } \\
\text { dialogue with customers. }\end{array}$ & $\varepsilon, r \wedge$ & $\cdot, V \vee Y$ \\
\hline $\begin{array}{l}\text { У. Increase the customers' positive } \\
\text { expectations of products and } \\
\text { services that are provided in } \\
\text { hotels. }\end{array}$ & $r, 9 V$ & $\cdot, \mathrm{VAT}$ \\
\hline ^. Support & $\varepsilon, 1 T$ & $\cdot, 7 \cdot 9$ \\
\hline
\end{tabular}


The Role of Online Guest Review Sites in the Hospitality Industry: Evidences from Managers' Perspectives

\begin{tabular}{|c|c|c|}
\hline $\begin{array}{l}\text { commercial activities (e.g., Pricing } \\
\text { information, customer services \& } \\
\text { facilities...etc). }\end{array}$ & & \\
\hline $\begin{array}{l}\text { 9. Reduce hotel's investment in other } \\
\text { traditional advertising media like } \\
\text { newspaper, TV advertising, and } \\
\text { billboards.... etc. }\end{array}$ & $\varepsilon,{ }_{1}$ & $\cdot, \vee \wedge \wedge$ \\
\hline $\begin{array}{l}\text { 1. Assist to avoid losing your market } \\
\text { share to competitors who are } \\
\text { already using them. }\end{array}$ & $\varepsilon, \Gamma \varepsilon$ & $\cdot, \vee \leqslant 0$ \\
\hline $\begin{array}{l}\text { 11. Are guiding guest to purchase and } \\
\text { react. }\end{array}$ & $\varepsilon, Y_{0}$ & $\cdot, \Lambda \cdot r$ \\
\hline $\begin{array}{l}\text { IY. Help to advertise hotel's } \\
\text { products/services. }\end{array}$ & $\Gamma, \wedge \varepsilon$ & $\cdot, \vee \vee V$ \\
\hline $\begin{array}{l}\text { IT. Provide quick initial response to } \\
\text { your guest reviews and respond } \\
\text { with clear and visible hotel's } \\
\text { identity. }\end{array}$ & $\varepsilon, \xi \leqslant$ &., $07 \varepsilon$ \\
\hline $\begin{array}{l}\text { 1ะ. Participate effectively in handling } \\
\text { guest complaints. }\end{array}$ & $\xi, \xi)$ & $\cdot, V \backslash r$ \\
\hline $\begin{array}{l}\text { 10. Build up the hotel reputation and } \\
\text { global brand name. }\end{array}$ & $\varepsilon, \Gamma \wedge$ &., 77. \\
\hline $\begin{array}{l}\text { 17. Respond to market trends and } \\
\text { competitive pressure. }\end{array}$ & $\varepsilon, \Gamma \wedge$ & $\cdot, V \cdot V$ \\
\hline Total & $\varepsilon, r \mu$ & $\cdot, V \leqslant V$ \\
\hline
\end{tabular}


In terms of the researched respondents' perceptions of the benefits of online guest review sites, the data presented in Table \& reveal that overall, the investigated respondents strongly agreed that guest review sites play an important role in improving hotel performance and become a vital issue in hotel industry that should be considered. They strongly agreed on the majority of the surveyed variables ( 1 - items out of 17 ) with an average mean ranged from $M=$ $\varepsilon, Y \circ$ to $M=\varepsilon, 0$. and agreed on the rest variables ( $~ T$ items of 17 ).

Results revealed that the highest advantage of online guest review sites is that guest review sites are valuable tools for distributing information and gathering data of customers' hotel experience $(\mathrm{M}=\{, 0 \cdot \mathrm{SD}=\cdot, \mathrm{T} r \mathrm{r})$. Additionally, more advantages, that arranged according to average mean, could be achieved as follows:

- Providing quick initial response to guest reviews and respond with clear and visible hotel's identity.

- Improving customer trust and confidence of hotel business.

- Participating effectively in handling guest complaints.

- Building up the hotel reputation and global brand name.

- Responding to market trends and competitive pressure.

- Assisting to avoid losing market share to competitors who are already using them. 
The Role of Online Guest Review Sites in the Hospitality Industry: Evidences from Managers' Perspectives

- Reducing hotel's investment in other traditional advertising media like newspaper, TV advertisement and billboards.

On the other hand, the least advantage was (Helping to advertise hotel's products/services) with an average mean $(\mathrm{M}=r, \wedge \varepsilon, \mathrm{SD}=\cdot, \vee \uparrow \vee)$, followed by being important to build relationship with customers and facilitate hotel-toconsumer interaction, and increase the customers' positive expectations of products and services that are provided in hotels with an average mean $r, q \leq$ and $r, q \vee$ respectively.

These findings match with the findings of different studies that addressed and explored the Pros of online guest review sites in the hospitality industry (Blal \& Sturman, Y.। $\leqslant$; Zhao, Wang, Guo, \& Law, $r \cdot 10$ and Amatulli, De Angelis \& Stoppani, $r \cdot 19$ ). They mentioned that online customer reviews could help hotels achieve various benefits, such as a closer relationship with customers by allowing them to read reviews from a variety of customers, respond to both positive and negative reviews, handle customer complaints (if applicable), and demonstrate that they care about what customers have to say. The impact of internet visibility on gross and net profitability is greater for hotels with higher star ratings. Each review made online by a customer is a kind of free advertisement for the business. Increasing trust and confidence in new customers (reviews can increase the confidence of new consumers if a product has good ratings or can simply be reviewed).

¿,o Perceptions of the Investigated Respondents towards Disadvantages of Online Guest Review sites

This question aims at identifying the perceptions of the investigated respondents towards the disadvantages of 
online guest review sites. A five-point Likert-type scale ( $1=$ strongly disagree to ${ }^{\circ}=$ strongly agree) was used. The data collected from the investigated respondents are illustrated in the following table.

Table $\varepsilon$ : Disadvantages of online guest reviews sites

\begin{tabular}{|c|c|c|}
\hline Variable & $\begin{array}{c}\text { Mea } \\
\mathrm{n}\end{array}$ & SD. \\
\hline $\begin{array}{l}\text { Misusing or abusing from guests to } \\
\text { decrease the hotel's rating or to ask } \\
\text { for a discount. }\end{array}$ & $\varepsilon, Y_{0}$ & 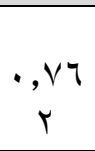 \\
\hline $\begin{array}{ll}\text { Fake reviews } & \text { (usually done by } \\
\text { competitors } & \text { and disgruntled } \\
\text { employees). } & \end{array}$ & $\varepsilon, \Gamma \varepsilon$ & $\cdot, \mathrm{V} \leqslant$ \\
\hline $\begin{array}{l}\text { Guests focus only on negative } \\
\text { reviews. }\end{array}$ & $r, 19$ & $\begin{array}{lll}1, Y \wedge \\
1\end{array}$ \\
\hline $\begin{array}{l}\text { Outdated Reviews (Having reviews } \\
\text { that are a year old can be hazardous). }\end{array}$ & $r, 91$ & $\begin{array}{c}1, Y v \\
q\end{array}$ \\
\hline $\begin{array}{l}\text { Few negative reviews could be able } \\
\text { to lose customers' confidence. }\end{array}$ & $\varepsilon, Y \wedge$ & $e_{4}^{4}$ \\
\hline
\end{tabular}

As mentioned in Table \&, it could be noticed that the majority of the investigated respondents strongly agreed that fake reviews that usually were done by competitors and disgruntled employees is considered the highest disadvantage of online guest reviews $(\mathrm{M}=\varepsilon, \Gamma \varepsilon)$. Moreover, they strongly agreed that few negative reviews and misusing or abusing from guests to decrease the rating of the hotel online or to ask for a discount could be able to lose customers' confidence with an average mean $\Sigma, \nvdash \wedge$ and $\varepsilon$, ro respectively. Meanwhile, they are neutral that guest focus only on negative reviews $(M=r, 19)$. These findings 
The Role of Online Guest Review Sites in the Hospitality Industry: Evidences from Managers' Perspectives

are consistent with Hlee, Lee, Koo \& Chung ( $\left.Y \cdot Y_{1}\right)$ and $\mathrm{Wu}, \mathrm{Ngai}, \mathrm{Wu} \& \mathrm{Wu}\left(Y_{\bullet} \mathrm{r}_{\bullet}\right)$ who concluded that fake reviews by disgruntled employee or malicious individual or competitors who post these reviews to lower the business rating, affect negatively on business performance. Fake reviews, they claimed, reduce the usefulness, quality, and informativeness of online product reviews. Fake reviews also detract from the trustworthiness of reviews and reduce their usefulness.

\section{Testing the Study Hypotheses}

Before testing the study's hypotheses, the researchers used the Kolmogorov- Smirnova and Shapiro Wilk tests to identify the normality of participants' responses, if the responses of the investigated respondents towards the study variables concerning advantages and disadvantages of online guest review sites follow the normal distribution or not.

Table $\bullet$ : Tests of normality

\begin{tabular}{|c|c|c|c|c|c|c|}
\hline \multirow{2}{*}{ Dimension } & \multicolumn{3}{|c|}{$\begin{array}{c}\text { Kolmogorov- } \\
\text { Smirnova }\end{array}$} & \multicolumn{3}{c|}{ Shapiro-Wilk } \\
\cline { 2 - 7 } & statistic & df & sig. & statistic & df & sig. \\
\hline $\begin{array}{c}\text { Advantages } \\
\text { and } \\
\text { disadvantages } \\
\text { of online guest } \\
\text { review sites }\end{array}$ & $.1 . \varepsilon$ & $r r$ & $. r .$. & $.9 \vee v$ & $r r$ &.$\vee \cdot$ \\
\hline
\end{tabular}

From data shown in Table ${ }^{\circ}$, it could be concluded that the distribution of responses of the investigated respondents towards the study variables concerning advantages and 
disadvantages of online guest review sites follow the normal distribution (parametric) where KolmogorovSmirnova and Shapiro-Wilk tests illustrated that there were no statistically significant differences $P>\cdot, \cdot 0$.

$H$ ': There are no statistically significant differences between perceptions of the investigated respondents towards advantages \& disadvantages of online guest review sites that refer to gender.

The independent t-test was performed to evaluate this hypothesis. The independent t-test is used to see if there's a statistically significant difference between two unrelated groups' means.

Table 7 : Differences between perceptions of the investigated respondents towards advantages $\&$ disadvantages of online guest review sites that refer to gender

\begin{tabular}{|c|c|c|c|c|c|}
\hline Dimension & Variable & Mean & $\begin{array}{c}\text { Std. } \\
\text { deviation }\end{array}$ & $t$ & Sig. \\
\hline \multirow{2}{*}{$\begin{array}{l}\text { Advantages } \\
\text { and } \\
\text { disadvantages } \\
\text { of online } \\
\text { guest review } \\
\text { sites }\end{array}$} & Male & $\varepsilon .9$ & 199 & \multirow[b]{2}{*}{ צ צז, • } & \multirow[b]{2}{*}{$\cdot, \times 19$} \\
\hline & Female & $\varepsilon, \cdot V$ & .181 & & \\
\hline
\end{tabular}

Significant at $P \leq \cdot, \cdot 0$

The results of the statistical analysis presented in Table 7 reveal that there are no statistically significant differences between the perceptions of the investigated respondents towards advantages \& disadvantages of online guest review sites refers to gender, where $\mathrm{P}>\cdot, \cdot \bullet$. Consequently, the null hypotheses "There are no statistically significant 
The Role of Online Guest Review Sites in the Hospitality Industry: Evidences from Managers' Perspectives

differences between the perceptions of the investigated respondents towards advantages \& disadvantages of online guest review sites refers to gender" is supported in favor of the alternative hypothesis "There are statistically significant differences between perceptions of the investigated respondents towards advantages \& disadvantages of online guest review sites refers to gender".

$H$ r: There are no statistically significant differences between perceptions of the investigated respondents towards advantages \& disadvantages of online guest review sites that refer to age.

The one-way ANOVA test was employed to evaluate this hypothesis. The one-way ANOVA test is performed to see if there are any statistically significant differences between three or more independent (unrelated) groups' means.

Table $\vee$ : Differences between perceptions of the investigated respondents towards advantages \& disadvantages of online guest review sites that refer to age

\begin{tabular}{|c|c|c|c|c|c|c|}
\hline \multicolumn{2}{|c|}{ Variable } & $\begin{array}{l}\text { Sum of } \\
\text { Squares }\end{array}$ & df & $\begin{array}{l}\text { Mean } \\
\text { Square }\end{array}$ & $\mathrm{F}$ & Sig. \\
\hline \multirow{3}{*}{$\begin{array}{l}\text { Advantages and } \\
\text { disadvantages of } \\
\text { online guest } \\
\text { review sites }\end{array}$} & \begin{tabular}{|l} 
Between \\
Groups
\end{tabular} &.$T r$ & $r$ & $.1 \mathrm{~V}$ & \multirow{3}{*}{$0 \vee \varepsilon$} & \multirow{3}{*}{.079} \\
\hline & $\begin{array}{l}\text { Within } \\
\text { Groups }\end{array}$ & . $1 \Gamma_{0}$ & rq & \multirow[t]{2}{*}{.$r^{q}$} & & \\
\hline & Total & .171 & T & & & \\
\hline
\end{tabular}

Significant at $P \leq \cdot . \bullet$

Data illustrated in Table $\vee$ reveal that $P$-value $=.7 \wedge 7$ is greater than the significance level $(P \leq \cdot, \cdot 0)$ which mean that null hypotheses "There are no statistically significant differences between perceptions of the investigated 
respondents towards advantages \& disadvantages of online guest review sites that refer to age" is supported in favor of the alternative hypothesis.

$H^{r}$ : There are no statistically significant differences between perceptions of the investigated respondents towards advantages \& disadvantages of online guest review sites that refer to level of education.

The independent t-test was performed to evaluate this hypothesis.

Table ^: Differences between perceptions of the investigated respondents towards advantages \& disadvantages of online guest review sites that refer to level of education

\begin{tabular}{|c|c|c|c|c|c|}
\hline Dimension & Variable & Mean & $\begin{array}{c}\text { Std. } \\
\text { deviation }\end{array}$ & $t$ & Sig. \\
\hline \multirow{2}{*}{$\begin{array}{l}\text { Advantages } \\
\text { and } \\
\text { disadvantages } \\
\text { of online } \\
\text { guest review } \\
\text { sites }\end{array}$} & $\begin{array}{c}\text { University } \\
\text { degree }\end{array}$ & $\varepsilon, \cdot V Y r$ & 11. & \multirow[b]{2}{*}{ ov. } & \multirow[b]{2}{*}{$.0 V r$} \\
\hline & $\begin{array}{l}\text { Post- } \\
\text { graduate } \\
\text { degree }\end{array}$ & $\{, 1.91$ & $1 \leqslant 1$ & & \\
\hline
\end{tabular}

Significant at $\mathrm{P} \leq \cdot, \cdot 0$

Table $\wedge$ shows that there are no statistically significant variations between the perceptions of the investigated respondents regarding the advantages and disadvantages of online guest review sites when level of education is considered, with $\mathrm{P}>\because \cdot{ }^{\circ}$. Consequently, the null hypotheses "There are no statistically significant differences between the perceptions of the investigated respondents towards advantages $\&$ disadvantages of online 
The Role of Online Guest Review Sites in the Hospitality Industry: Evidences from Managers' Perspectives

guest review sites that refer to level of education" is supported in favor of the alternative hypothesis".

$H^{\xi}$ : There are no statistically significant differences between perceptions of the investigated respondents towards advantages \& disadvantages of online guest review sites that refer to length of work experience.

The one-way ANOVA test was employed to evaluate this hypothesis.

Table 9 : Differences between perceptions of the investigated respondents towards advantages \& disadvantages of online guest review sites that refer to length of work experience

\begin{tabular}{|c|c|c|c|c|c|}
\hline Variable & $\begin{array}{l}\text { Sum of } \\
\text { Squares }\end{array}$ & df & $\begin{array}{l}\text { Mean } \\
\text { Square }\end{array}$ & $\mathrm{F}$ & Sig. \\
\hline \multirow{3}{*}{$\begin{array}{l}\text { Advantages and } \\
\text { disadvantages of } \\
\text { online guest } \\
\text { review sites }\end{array}$} & $\ldots r$ & $r$ & $\cdots r$ & \multirow{3}{*}{.07} & \multirow{3}{*}{$.9 \leq 0$} \\
\hline &.$\wedge 9 \vee$ & rq & .4 & & \\
\hline & 9.1 & Tा & & & \\
\hline
\end{tabular}

The results of the statistical analysis presented in Table 9 reveal that there are no statistically significant differences between the perceptions of the investigated respondents towards advantages $\&$ disadvantages of online guest review sites refers to work experience, where $\mathrm{P}>\cdot, \cdot 0$. Consequently, the null hypotheses "There are no statistically significant differences between the perceptions of the investigated respondents towards advantages \& disadvantages of online guest review sites refers to length 
of work experience" is supported in favor of the alternative hypothesis.

\section{- Conclusion and Implications of the study}

To conclude, the present study indicates that the investigated respondents perceived that guest review sites play an important role in hospitality industry. Guest reviews and responding to them on time have always been a vital part of the hotel industry. With regard to advantages of GRS, they are a way for travelers to share their experiences with other potential hotel guests, and they can be used in gathering data of customers' hotel experience which may be a valuable tool to improve the quality of hospitality services provided, improve customer trust and confidence of hotel business, participate effectively in handling guest complaints, and building up the hotel reputation and global brand name. On the other hand, the highest disadvantage of online guest review sites was fake reviews that usually done by competitors and disgruntled employees, which affect negatively on hotel's image, reputation, and performance.

Overall, the investigated respondents confirmed that they review and respond to guest reviews on a regular base which reflect their responsiveness to online guest reviews. TripAdvisor.com and Booking.com were the most used hotel guest review sites to identify the guests' perceptions towards the quality of their hotel experience. With regard to the motivation to engage in reviewing online guest review sites, the findings of the study reveal that improving the hotel's image and reputation among customers and competitors was the main factor.

Finally, the study findings reveal that there are no statistically significant differences between perceptions of 
The Role of Online Guest Review Sites in the Hospitality

Industry: Evidences from Managers' Perspectives

the investigated respondents towards advantages \& disadvantages of online guest review sites that refer to gender, age, level of education, and length of work experience which reflect the homogeneity of the investigated respondents towards advantages and disadvantages of online guest review sites, despite of their difference in gender, age, level of education, and length of work experience.

Upon the study findings, the study has several implications for hotel managers. Firstly, hoteliers should participate actively in online consumer communities and provide all relevant and full information about their hotels. Secondly, hotel operators should be more committed to increasing customer reviews, reviewing, and responding to them, especially the negative ones. Encouraging customers to participate in posting reviews about their hotel experience, will mitigate the demonstrably negative effects of negative reviews, and will allow them to approach their true average score more quickly. Thirdly, online reviews can be a valuable resource as hotel operators seek to improve their operational effectiveness. So, hotel managers should be considering the customers' reviews that lead to explore the areas that need recovering and improvement. Fourthly, a strategy for dealing with negative internet reviews should be included in a larger company strategy for assessing customer satisfaction and engagement. Fifthly, to stay on top of what guests are saying about you on review sites, blogs, and social media, employ social listening tools or a hotel reputation management system with real-time notifications. Finally, hotel managers should respond to customers' reviews as quickly as possible. When responding to a complaint, acknowledge the negative 
experience, apologise, stress the improvements, and follow up.

\section{References}

Amatulli, C., De Angelis, M., \& Stoppani, A. (ץ.19). Analyzing online reviews in hospitality: data-driven opportunities for predicting the sharing of negative emotional content. Current issues in tourism, $r$ r $(10), 19 . \varepsilon_{-}$ $191 \mathrm{~V}$.

Aureli, S., \& Supino, E. $(\uparrow \cdot \mid \vee)$. Online Reputation Monitoring: An exploratory study on italian hotel managers' practices. International Journal of Hospitality \& Tourism Administration, $1 \wedge(1), \wedge \varepsilon_{-} 1 \cdot 9$.

Baltescu, C. A. $(Y \cdot 17)$. Are online guest reviews useful? Implications for the hotel management. Annales Universitatis Apulensis: Series Oeconomica, $1 \wedge(r), 10$.

Blal, I., \& Sturman, M. C. ( $r) \varepsilon)$. The differential effects of the quality and quantity of online reviews on hotel room sales. Cornell Hospitality Quarterly, 00(₹), rro_rvo.

Brown, T. J., Barry, T. E., Dacin, P. A., \& Gunst, R. F. $(r \cdots O)$. Spreading the word: Investigating antecedents of consumers' positive word-of-mouth intentions and behaviors in a retailing context. Journal of the academy of marketing science, $r r_{(}(r),\left|r r_{-}\right| r \Lambda$.

Buhalis, D., \& Law, R. ( $\left.r_{\cdots \wedge}\right)$. Progress in information technology and tourism management: $r \cdot$ years on and $1 \cdot$ years after the Internet-The state of eTourism research. Tourism management, $r q(\varepsilon), 7.9-7 r r$. 
Bulchand-Gidumal, J., Melián-González, S., \& López-Valcárcel, B. G. $(\uparrow \cdot 11)$. Improving hotel ratings by offering free Wi-Fi. Journal of Hospitality and Tourism Technology.

Cantallops, A. S., \& Salvi, F. (Y.। $)$ ). New consumer behavior: A review of research on eWOM and hotels. International Journal of Hospitality Management, $\left.\Gamma^{\top}, \varepsilon\right)_{-} 0$ ).

Casalo, L. V., Flavian, C., Guinaliu, M., \& Ekinci, Y. $(\Upsilon \cdot 10)$. Do online hotel rating schemes influence booking behaviors? International Journal of Hospitality

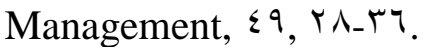

Chen, Y., Fay, S., \& Wang, Q. (Y. I). The role of marketing in social media: How online consumer reviews evolve. Journal of interactive marketing, ${ }^{\circ}(r),{ }^{\prime} 0_{-} \uparrow$.

Cheng, V. T., \& Loi, M. K. (Y.I乏). Handling negative online customer reviews: the effects of elaboration likelihood model and distributive justice. Journal of Travel \& Tourism Marketing, rI(1), ।-10.

Chevalier, J. A., \& Mayzlin, D. ( $r \ldots \uparrow)$. The effect of word of mouth on sales: Online book reviews. Journal of marketing research, $\leqslant r(r), r \leqslant 0_{-} r o \leqslant$.

Clemons, E. K., Gao, G. G., \& Hitt, L. M. ( $(\cdots\urcorner)$. When online reviews meet hyperdifferentiation: A study of the craft beer industry. Journal of management information systems, $r \Psi(r), \backslash \leq q_{-} \mid Y \backslash$.

Dellarocas, C. $(\uparrow \cdots r)$. The digitization of word of mouth: Promise and challenges of online feedback mechanisms. Management science, $\left.\leqslant 9(1 \cdot), 1 \leqslant \cdot v_{-}\right) \leqslant r \leqslant$.

Dellarocas, C., Zhang, X. M., \& Awad, N. F. ( $(\cdots \vee)$. Exploring the value of online product reviews in 
forecasting sales: The case of motion pictures. Journal of Interactive marketing, $Y \backslash(\varepsilon), r r-\varepsilon 0$.

Dhar, V., \& Chang, E. A. ( $r \cdot q)$. Does chatter matter? The impact of user-generated content on music sales. Journal of Interactive Marketing, $r \Psi(\varepsilon), r \cdots \cdot r \cdot v$.

DoubleClick's Touchpoints, I. I. $(r \cdots \varepsilon)$. The changing purchase process. Double-Click, March.

Egyptian Hotel Association ( $(\cdot 17)$. Egyptian Hotel Guide, $r \varepsilon$ th edition. Cairo, Egypt.

Etikan, I., Musa, S. A., \& Alkassim, R. S. ( $(\cdot 17)$. Comparison of convenience sampling and purposive sampling. American journal of theoretical and applied statistics, ${ }^{\circ}(1), 1-\varepsilon$.

Fiedler, M., \& Kissling, M. $(r \cdot r \cdot)$. Fake Reviews In ·eCommerce Marketing.

Filieri, R. $(r \cdot 10)$. What makes online reviews helpful? A diagnosticity-adoption framework to explain informational and normative influences in e-WOM. Journal of business research, $T \wedge(T),|r T|-\mid r V \cdot$.

Filieri, R., \& McLeay, F. (Y.) $)$ ). E-WOM and accommodation: An analysis of the factors that influence travelers' adoption of information from online reviews. Journal of travel research, or ( 1$)$, $\leqslant$ 纟_ov.

Gretzel, U., \& Yoo, K. H. ( $\uparrow \cdots \wedge)$. Use and impact of online travel reviews. Information and Communication Technologies in Tourism, $\Gamma_{-} \leqslant$.

$\mathrm{Gu}$, B., \& Ye, Q. $(r \mid))$. First step in social media: Measuring the influence of online management responses on customer satisfaction. Production and Operations Management, $r$ r $(\varepsilon)$, ov • - ONr.

Hlee, S., Lee, H., Koo, C., \& Chung, N. (Y.Y ). Fake Reviews or Not: Exploring the relationship between time 
trend and online restaurant reviews. Telematics and Informatics, 09, 1.107.

Kim, W. G., Lim, H., \& Brymer, R. A. $\left(r^{\prime} 10\right)$. The effectiveness of managing social media on hotel performance. International Journal of Hospitality Management, $\leqslant\left\{, 170_{-} \mid \mathrm{V}\right.$.

Kwok, L., Xie, K. L., \& Richards, T. ( $(\cdot \mid \vee)$. Thematic framework of online review research: A systematic analysis of contemporary literature on seven major hospitality and tourism journals. International Journal of Contemporary Hospitality Management.

Lavrakas, P.J. ( $¥ \cdots \wedge)$. Encyclopedia of Survey Research Methods; SAGE Publications: Thousand Oaks, CA, USA.

Levy, S. E., Duan, W., \& Boo, S. (Y.IT). An analysis of one-star online reviews and responses in the Washington, DC, lodging market. Cornell Hospitality Quarterly, $0 \leqslant(1)$, 纟ุ_tr.

Liang, S. W. J., Ekinci, Y., Occhiocupo, N., \& Whyatt, G. $(r \cdot 1 r)$. Antecedents of travellers' electronic word-of-mouth communication. Journal of Marketing Management, ${ }^{q}\left(\theta_{-}\right.$ 7), $0 \wedge \varepsilon-7 \cdot 7$.

Litvin, S. W., Goldsmith, R. E., \& Pan, B. ( $¥ \cdots \wedge)$. Electronic word-of-mouth in hospitality and tourism management. Tourism management, $q(r),\left\{0 \Lambda_{-} \leqslant \uparrow \Lambda\right.$.

Molinillo, S., Fernández-Morales, A., Ximénez-deSandoval, J. L., \& Coca-Stefaniak, A. $\left(r_{\cdot}\right)$ \%). Hotel assessment through social media-TripAdvisor as a case study. Tourism \& Management Studies, $M(1), 10_{-} r$.

O'connor, P. $\left(Y \cdot r^{\cdot}\right)$. Managing a hotel's image on TripAdvisor. Journal of hospitality marketing \& management, $19(\mathrm{~V}), \mathrm{V} 0 \varepsilon_{-} \mathrm{VVY}$. 
O'connor, P. $(Y \cdot) \cdot)$. Managing a hotel's image on TripAdvisor. Journal of hospitality marketing \& management, $19(\mathrm{~V}), \mathrm{V} 0 \varepsilon_{-} \mathrm{V} V \mathrm{Y}$.

Pan, B., MacLaurin, T., \& Crotts, J. C. ( $($..V). Travel blogs and the implications for destination marketing. Journal of travel research, $\Sigma\rceil(1)$, ro_ $\leqslant$.

Racherla, P., Mandviwalla, M., \& Connolly, D. J. ( $(\cdot 1 r)$. Factors affecting consumers' trust in online product reviews. Journal of Consumer Behaviour, $\left.11(Y), 9 \varepsilon_{-}\right) \cdot \varepsilon$.

Sayfuddin, A. T. M., \& Chen, Y. $(Y \cdot Y)$ ). The signaling and reputational effects of customer ratings on hotel revenues: Evidence from TripAdvisor. International Journal of Hospitality Management, $99,1 \cdot r \cdot 70$.

Schuckert, M., Liu, X., \& Law, R. $\left(\Upsilon^{\circ}{ }^{\circ}\right)$. Hospitality and tourism online reviews: Recent trends and future directions. Journal of Travel \& Tourism Marketing, rY(0), T. A_TYl.

Sen, S., \& Lerman, D. $(Y \cdots \vee)$. Why are you telling me this? An examination into negative consumer reviews on the web. Journal of interactive marketing, $Y \backslash(\xi), \vee \tau_{-} q \varepsilon$.

Sigala, M., Christou, E., \& Gretzel, U. (Eds.). $(r \cdot M)$. Social media in travel, tourism and hospitality: Theory, practice and cases. Ashgate Publishing, Ltd..

Sparks, B. A., \& Browning, V. $(r \cdot 11)$. The impact of online reviews on hotel booking intentions and perception of trust. Tourism management, $r(\tau), 1 r 1 \cdot-1 \mu r r$.

TripAdvisor. Available on: https://www.statista.com/study/\&r $\Sigma \vee \varepsilon /$ tripadvisor/ (Accessed - September $\left.r \cdot r^{\prime}\right)$.

Vermeulen, I. E., \& Seegers, D. ( $\uparrow \ldots q)$. Tried and tested: The impact of online hotel reviews on consumer consideration. Tourism management, $r \cdot(1), 1 r \mu-1 Y v$. 
Wu, Y., Ngai, E. W., Wu, P., \& Wu, C. (Y.r•). Fake online reviews: Literature review, synthesis, and directions for future research. Decision Support Systems, Irr, IIrrA. Xiang, Z., \& Gretzel, U. (Y.l•). Role of social media in online travel information search. Tourism management, $r \backslash(r), \mid \vee q_{-} \backslash \wedge \wedge$.

Xie, K. L., Zhang, Z., \& Zhang, Z. (Y. I乏). The business value of online consumer reviews and management response to hotel performance. International Journal of Hospitality Management, $\{r, 1-1 r$.

Yang, Y., Mueller, N. J., \& Croes, R. R. ( .17$)$. Market accessibility and hotel prices in the Caribbean: The moderating effect of quality-signaling factors. Tourism Management, 07, $\{\cdot-01$.

Yap, K. B., Soetarto, B., \& Sweeney, J. C. (Y.Ir). The relationship between electronic word of-mouth motivations and message characteristics: The sender's perspective.

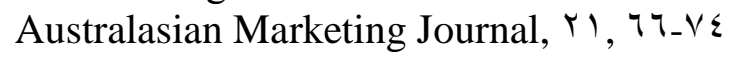

Zhang, D., Zhou, L., Kehoe, J. L., \& Kilic, I. Y. (ץ.17). What online reviewer behaviors really matter? Effects of verbal and nonverbal behaviors on detection of fake online reviews. Journal of Management Information

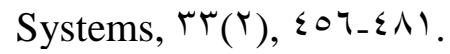

Zhao, X. R., Wang, L., Guo, X., \& Law, R. (Y.10). The influence of online reviews to online hotel booking intentions. International Journal of Contemporary Hospitality Management. 